\title{
Aspects Regarding the Value of the Treatment of Surgically Induced Menopause with Phytoestrogens - a Postmarketing Surveillance Study (PMSS)
}

\section{Doru ANASTASIUa, Adrian GLUHOVSCHI ${ }^{a}$, Olivera IORDACHEa ${ }^{a}$ Ramona ANDERCA ${ }^{a}$,} Virgil POPESCU ${ }^{\mathrm{b}}$, Brindusa PANA ${ }^{\mathrm{c}}$

a"Victor Babes" University of Medicine and Pharmacy, Timisoara, Department of Obstetrics, Gynecology, Neonatology and Puericulture, "Bega" Clinical Hospital of Obstetrics and Gynecology, Timisoara, Timis county, Romania

"Carol Davila" University of Medicine and Pharmacy, Bucharest, Romania

'Floreasca Clinical Emergency Hospital, Bucharest, Romania

\section{ABSTRACT}

Background: Premenopause and menopause are nowadays a matter of public health due to the increasing life expectancy for women. Medical issues related to the period of premenopause and menopause are important, since they can alter the quality of women's life.

Objective: The goal of this prospective study is to determine the effect of an original formula consisting of phytoestrogens extracted from soy germs (Glycyne hisipida) with $40 \%$ isoflavones, vitamin $E$ and grapeseed extract (Vitis vinifera) with $95 \%$ proanthocyanidins in reducing menopausal symptoms.

Material and methods: The present study had a six-month monitoring period in 2011 and involved four investigating physicians from "Bega" Clinical Hospital of Obstetrics and Gynecology, Timisoara, Romania.

Outcomes: After six months of therapy there was a percentually decrease in menopause symptoms (irritability, depression, anxiety, hot flashes, etc); the most dramatic changes in the symptomatology of these women were noticed among premenopausal subjects.

Conclusions: The original formula consisting of phytoestrogen, vitamin $E$ and grapeseed extract can be applied in premenopause and surgically-induced menopause, and it is beneficial by decreasing the intensity of the symptomatology.

Keywords: menopause, research, study, isoflavones, soybeans, grape seed extract, vitamin E.

\section{INTRODUCTION}

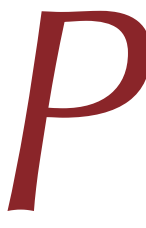

remenopause and menopause are nowadays a matter of public health due to the increasing life expectancy for women. Medical issues related to the period of premenopause and meno- pause are important $(1,2)$, since they can alter the quality of women's life. Health conditions related to premenopause or menopause are often causing marriage problems or predispose the onset of pathologies which are typical to elderly patients $(3,4)$. Under these conditions, an increasing number of women have turned to hormone replacement

\footnotetext{
Address for correspondence:

Dr. Brindusa PANA

Floreasca Clinical Emergency Hospital, Bucharest, Romania

Postal address: Turturelelor Str., No. 11A, Phoenicia Business Center, 2nd Floor, Ap. 18, Bucharest, Romania

Tel.: +40 747115486, email: brindusa.pana@hyllan.eu
} 
therapy. On the other hand, the risks of hormonal replacement therapy in menopause have become more and more debated (5-8). The potential risks of hormone replacement therapy mostly refer to oncologic risks (endometrial and breast cancer), thrombotic risks, metabolic risks and the influence of sterol hormones on various diseases. The benefits of hormonal replacement therapy are weighed against the potential risks more and more, attempting to take into consideration a series of precautions for the approach of this therapy (9-11). Yet, only $4-8 \%$ of Romanian women are using menopause treatment, most of them perceiving all changes occurring during menopause as being inherent to the aging process (12).

As an alternative to hormonal replacement treatment in menopause there is a non-hormonal therapy, which consists of antidepressants, phytoestrogens and homeopathic medication such as Radix cimicifuga, Sepia officinalis, Ignatia strupchnos, isoflavones, etc (13).

The natural formula tested in the present postmarketing surveillance study consists in phytoestrogens extracted from soy germs (Glycyne hisipida) with $40 \%$ isoflavones, vitamin $\mathrm{E}$ and grapeseed extract (Vitis vinifera) with 95\% proanthocyanidins. Our study included 60 female patients who were divided into two groups: the first one (group I) comprising 40 patients with surgical menopause after total hysterectomy with bilateral adnexectomy for severe diseases, and the second one (group II) comprised patients aged 41-55 going through natural premenopause.

\section{Objective}

The present study aims to identify an alternative to hormone replacement therapy in menopause which is both effective in reducing menopausal symptoms so that women could reach this point naturally and useful for those with surgical menopause (induced by hysterectomy with bilateral adnexectomy). Based on natural active principles, the studied formula may improve life comfort in menopausal women.

\section{MATERIAL AND METHODS}

The present study had a six-month monitoring period in 2011 and involved four investigating physicians from "Bega" Clinical Hospital of Obstetrics and Gynecology, Timisoara, Romania. It included 60 women who were divided into two groups: the first one (group I) comprising 40 women with surgical menopause after total hysterectomy with bilateral adnexectomy for severe diseases and the second one (group II) comprising women aged 41-55 going through premenopause. The first group was divided into two groups in its turn: group I A, consisting in premenopausal women aged between 41 and 55 (20 patients), and group I B, consisting in women over 50 who were already at menopause by the time they underwent surgery (20 patients).

All groups received the original formula consisting of phytoestrogen, vitamin $\mathrm{E}$ and grapeseed extract as a natural menopause symptoms therapy. For women subjected to surgical intervention, the treatment started 10 days after surgery. Patients were given one tablet of a natural formula consisting of phytoestrogens from soy germ, vitamin $\mathrm{E}$ and grapeseed extract daily for six months. The original formula is a proprietary formula of an authorized company, notified as a food supplement by INCDBA-IBA (National Research and Development of Food Institute) since 2009. To ensure the quality and benefits of the natural formula, the ingredients are standardized in active compounds: phytoestrogens extracted from soy germs (Glycyne hisipida) have $40 \%$ isoflavones and grapeseed extract (Vitis vinifera) have 95\% proanthocyanidins. Quality and safety search was performed for every batch of product. Each patient filled out a self-assessment sheet including questions about peri-menopausal and menopausal symptomatology, and a sexual behavior form with data regarding feminine sexual dysfunction, which was validated by FSFI (Female Sexual Functioning Index).

\section{Working hypotheses}

A postmarketing surveillance study was carried out, which provided data on the evolution of menopause symptoms under phytoestrogen therapy as well as that of symptomatology according to the type of menopause (natural or surgery-induced) and age when the surgical menopause was induced (under or over 50).

The research plan included family medical history, personal physiological and pathological history, and anthropometric measurements, including BMI data, gynecological examination at the beginning of the study and over its course, and 
TABLE 1. Parameters monitored in the present study according to integrated patient groups

\begin{tabular}{|l|l|l|l|l|l|l|l|l|l|l|l|}
\hline Symptoms & $\begin{array}{l}\text { Hot } \\
\text { flashes, } \\
\text { cold } \\
\text { sweat }\end{array}$ & $\begin{array}{l}\text { Precordial } \\
\text { pain }\end{array}$ & $\begin{array}{l}\text { Joint } \\
\text { pain }\end{array}$ & $\begin{array}{l}\text { Sleeping } \\
\text { disorders }\end{array}$ & Anxiety & Depression & Irritability & Tiredness & $\begin{array}{l}\text { Sexual } \\
\text { dysfunctions }\end{array}$ & $\begin{array}{l}\text { Urinary } \\
\text { incontinence }\end{array}$ & $\begin{array}{l}\text { Vaginal } \\
\text { atrophy }\end{array}$ \\
\hline $\begin{array}{l}\text { Group I A } \\
\%\end{array}$ & 70 & 10 & 35 & 45 & 40 & - & 55 & 85 & 20 & 35 & 15 \\
\hline $\begin{array}{l}\text { Group I B } \\
\%\end{array}$ & 10 & 5 & 65 & 10 & 5 & 10 & 5 & 90 & 70 & 90 & 90 \\
\hline Group II \% & 80 & 10 & 80 & 30 & 20 & 10 & 5 & 80 & 40 & 75 & 40 \\
\hline Total \% & 53.33 & 8.33 & 60 & 28.3 & 21.6 & 6.66 & 40 & 85 & 43.33 & 66.66 & 48.33 \\
\hline
\end{tabular}

monitoring of patients' evolution after six months of treatment.

The following inclusion and exclusion criteria were considered:

- Inclusion criteria: age above 41, patients premenopausal or menopausal women and patients with surgical menopause after total hysterectomy with bilateral adnexectomy for severe diseases.

- Exclusion criteria: patients who were using another treatment for menopause symptoms (hormonal or natural).

We appraised the following parameters: immediate symptoms which were common to menopause (hot flashes, cold sweat), precordial and joint pain, sleep disorders, anxiety, irritability, tiredness, sexual dysfunction, vaginal atrophy, depression, urinary incontinence (Table 1).

According to age, group I A comprised patients aged between 41 and 55 years, predominantly $46-50$ years (50\% of cases) (Figure 1), while in group I B the predominant age -10 women ( $50 \%$ of cases) - was 56-60 years (Figure 2). All these women were already menopausal when subjected to surgery. Group II comprised premenopausal women aged $41-55$ years (Figure 3 ) who did not undergo surgery and in whom premenopause happened naturally.

Taking into consideration the body mass index (BMI), most patients in all groups had various degrees of obesity, with a BMI above 25 [38 patients $(63.3 \%)]$, between 18 and 25 [14 patients (23.3\%)] and under 18 [eight patients (13.3\%)] (Figure 4).

Regarding the predominance of symptoms, the following percentages were registered for our 60 patients: hot flashes, cold sweat $53.3 \%$ of subjects), precordial pain $(8.33 \%)$, joint pain $(60 \%)$, sleeping disorders (28.3\%), anxiety (21.6\%), irritability $(40 \%)$, unusual tiredness $(85 \%)$, sexual dysfunction $(46.66 \%)$, urinary incontinence $(46.66 \%)$, vaginal atrophy $(48.33 \%)$ and depression $(6.66 \%)$.

There was a high degree of variation between the examined groups in terms of incidence of pre-

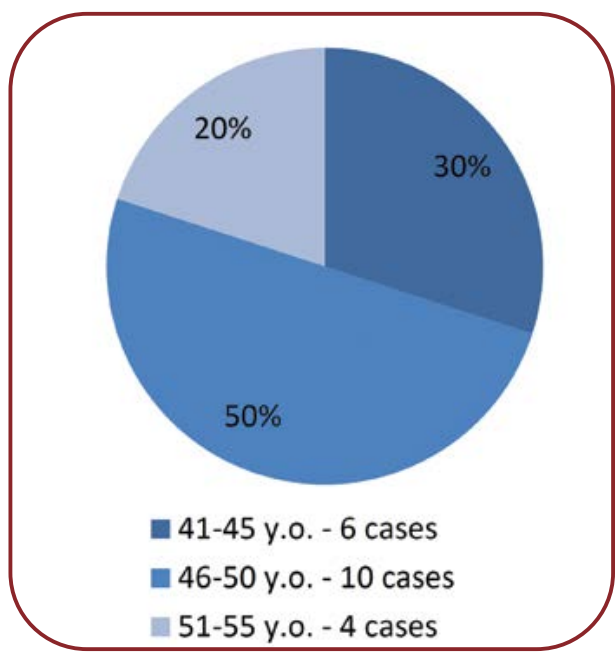

FIGURE 1. Patient allocation to group I A according to age

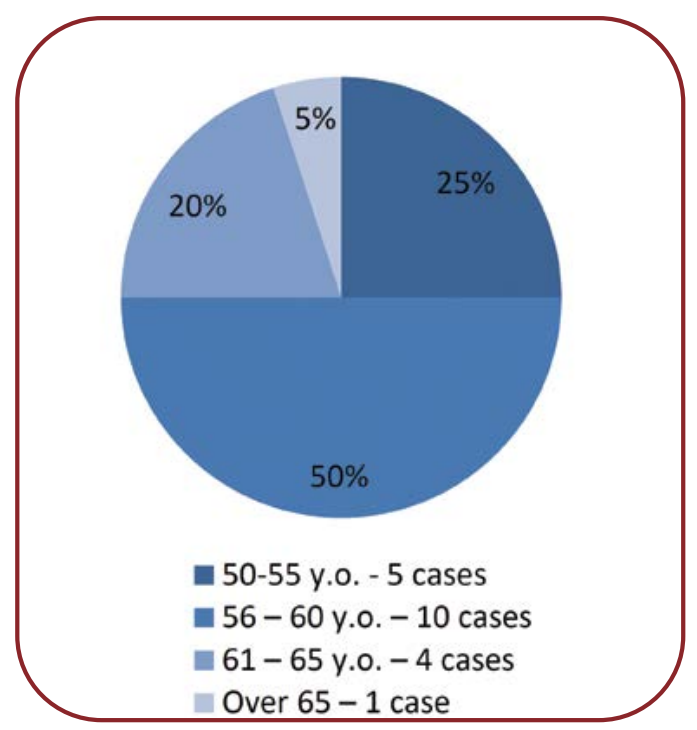

FI GURE 2. Patient allocation to group I B according to age 
menopause or menopause symptoms; the study has also taken into account the subjectivity criterion. Symptom intensity was assessed according to

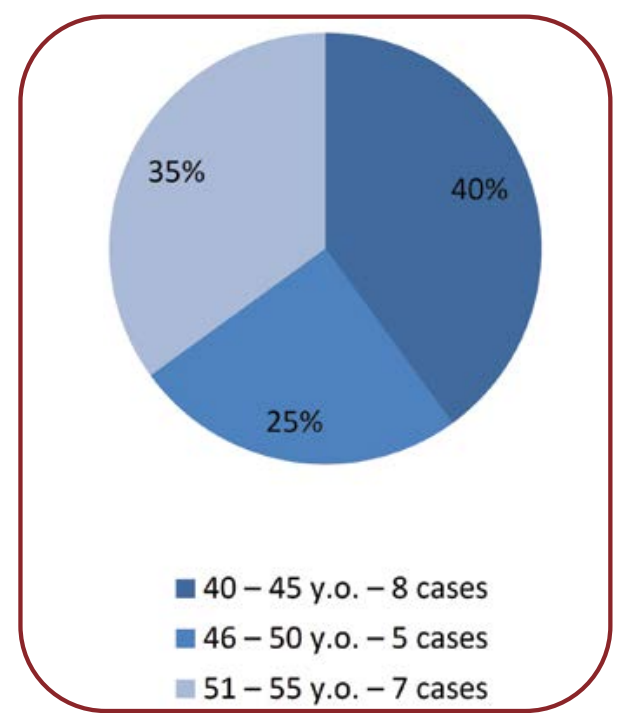

FIGURE 3. Patient allocation to group II according to age

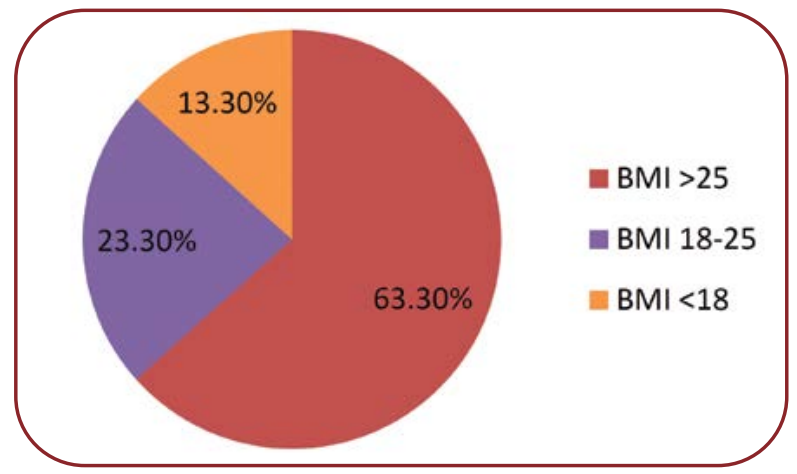

FIGURE 4. Patient allocation according to the body mass index (BMI) the following scale: absent, mild, moderate, severe and highly severe.

\section{RESULTS AND DISCUSSIONS}

After six months of treatment only with the Aoriginal formula consisting of phytoestrogen, vitamin E and grapeseed extract, a first re-evaluation was carried out. Figure 5 shows the decrease in symptom intensity expressed as percentages, in the decreasing order of study parameters.

The most dramatic changes in these women's symptomatology were seen among premenopausal women (groups I A and II). In group I A, eight women had premenopausal symptoms, half of which were noticed before the total hysterectomy with bilateral adnexectomy, with the hot flashes and cold sweat decreasing from $53.33 \%$ to $46.15 \%$. There was a gradual transition towards surgical menopause in terms of symptomatology onset.

Figure 6 illustrates the main menopausal symptoms in percentages at the beginning of the study vs after six-month treatment.

Subsequently to the phytoestrogen treatment there was a percentage decrease as well as a decrease in intensity for all analyzed symptoms.

\section{CONCLUSIONS}

The original formula consisting of phytoestrogen, vitamin $\mathrm{E}$ and grapeseed extract can be administered to patients with premenopause and surgically induced menopause, and it is beneficial by decreasing symptom intensity.

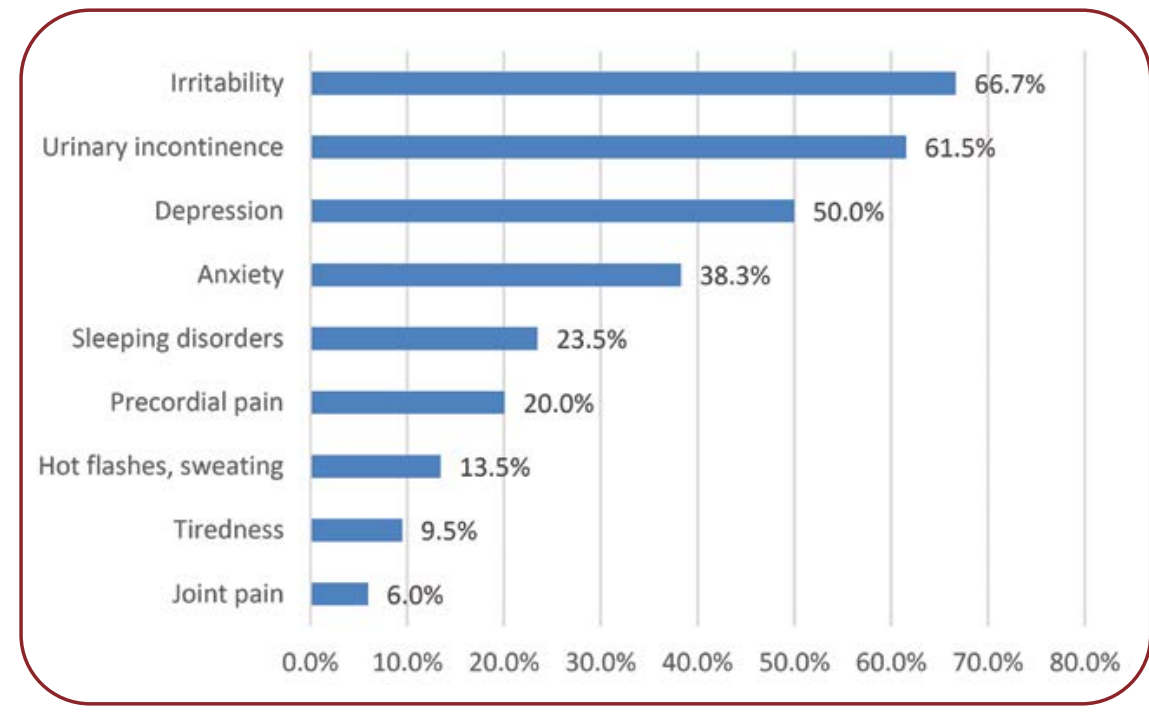

FIGURE 5. Percentually decrease in menopause symptoms subsequent to a six-month treatment with the original formula consisting of phytoestrogen, vitamin $\mathrm{E}$ and grapeseed extract 


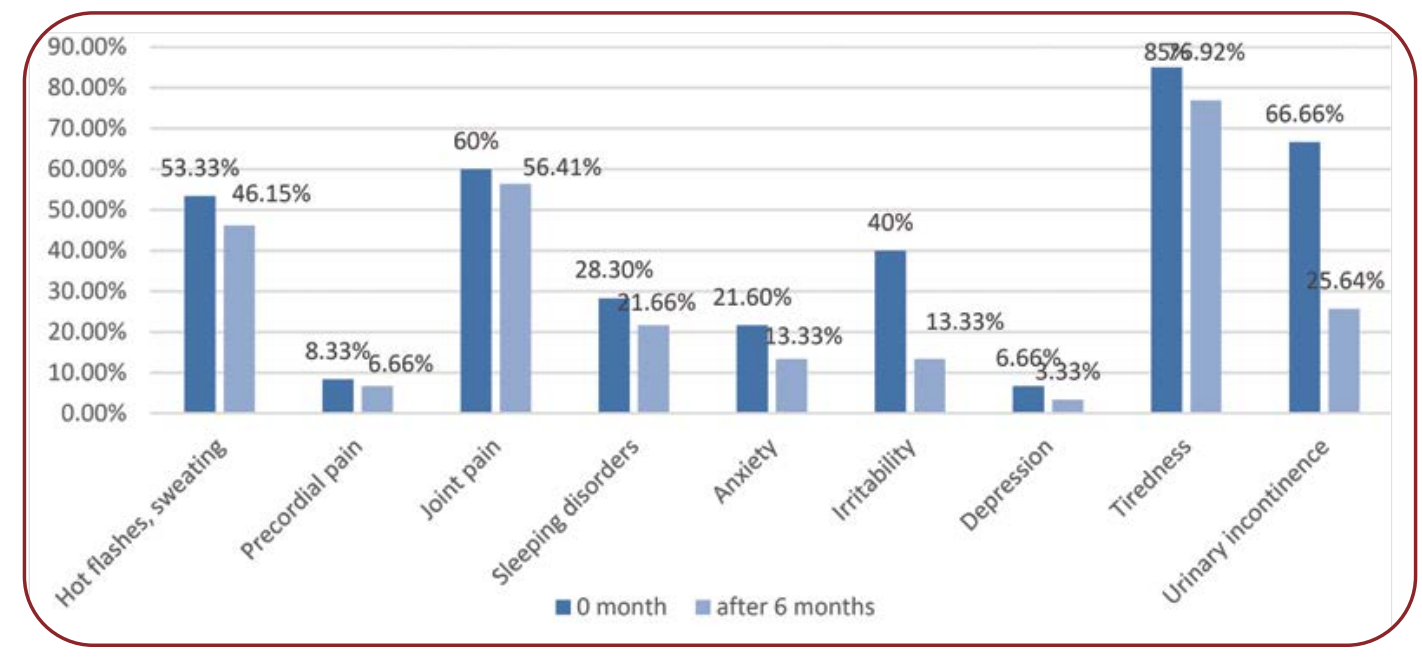

FIGURE 6. The comparative amendment of the main menopausal symptoms after six-month treatment with the original formula consisting of phytoestrogen, vitamin $\mathrm{E}$ and grapeseed extract
2. The therapy is effective in decreasing the main symptoms of menopause and had no side effects during the six months of study.

3. The postmarketing surveillance study shows that the effects are better among premenopausal women than menopausal ones.

4. Starting phytoestrogen therapy immediately after hysterectomy with bilateral adnexectomy reduces symptoms for a more comfortable transition to menopause.

5. Although symptom decrease in menopausal women who had a total hysterectomy with bilateral adnexectomy is not as visible as in pre- menopausal women, the main improvements were seen for tiredness, irritability, depression and joint pain, meaning that the administered therapy offered a better quality of life.

6. It can be stated that phytoestrogens trigger an endocrine mechanism that reduces not only tiredness, depression, irritability but also arthralgic, myalgic and nevralgic syndromes.

\section{Conflicts of interest: none declared.}

All products administered during the study were offered to patients for free by an authorized company.

\section{$\boldsymbol{R}_{\text {EFERENCES }}$}

1. Russu M. Imbatranirea urogenitala la menopauza, o veche problema medicala reactualizata. Conf Soc Ginec-endocrin, Madeira, 2008, pp 22-29.

2. Anastasiu D, Dema Alice, Dorneanu F, Gluhovschi A, Dumitrascu D. Modificari histologice vaginale in menopauza. Congr III Soc Endocrin Ginecol, Madeira, 2008, pp 29-32.

3. Anastasiu D, Craina M, Gluhovschi A, Dorneanu F, Anastasiu DM. Aspecte privind incontinenta urinara la menopauza. Congr III Soc Endocrin Ginecol, Madeira, 2008, pp 48-49.

4. Anastasiu D, Gluhovschi A, Anastasiu DM, Iordache O. Modificarile morfofunctionale in climateriu la femeile institutionalizate. Cong Nat Endocrin
Ginec, Madeira, 2008, pp 13-14.

5. Anastasiu D. Investigatii actuale si tratamentul pe cale vaginala a afectiunilor ginecologice. Teza de doctorat UMF "Victor Babes" Timisoara, 1999.

6. Anastasiu D. Obstetrica-Ginecologie. Prezentari de caz. Timisoara, Ed. Brumar, 2008.

7. Anastasiu D, David D, Campeanu L. Sexualitatea femeilor in postmenopauza, Sinaia. 2013

8. Gluhovschi A, Craina M, Iordache O, Anastasiu DM, Anastasiu D. Controverse privind implicarea perimenopauzei si menopauzei in modificarile morfofunctionale ale organismului asupra femeilor institutionalizate. In: P. Chitulea, Calitatea vietii femeii, 2012, pp 14-20.
9. Hurd WM. Menopauza. In: Novak, Ginecologie. Ed. Med. Callista, 1999, pp 981-1002.

10. McKinley SM, Brambilla DJ, Posner JG. The normal menopause transition. Maturitas 1992;4:103-155.

11. Palinkas SM, Shervin BB. Effects of estrogen on memory function. Psychoneuroendocrinology 1992;17:485-487.

12. Pelinescu-Onciul D. Menopauza. Ghid terapeutic, Ed. Diasfera, Bucuresti, 2000, pp 52-58.

13. US Food and Drug Administration. Bio-identicals: Sorting myths from facts http://www.fda.gov/Drugs/GuidanceComplianceRegulatoryInformation/ PharmacyCompounding/ucm049311.htm (Accessed on November 20, 2012). 